\title{
Correction to: Prognostic Assessment of Non-functioning Neuroendocrine Pancreatic Neoplasms as a Basis for Risk-Adapted Resection Strategies
}

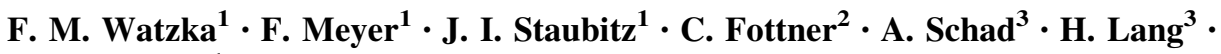

T. J. Musholt ${ }^{1}$

Published online: 12 February 2020

(C) Société Internationale de Chirurgie 2020

Correction to: World J Surg (2020) 44:594-603
https://doi.org/10.1007/s00268-019-05220-7

This article contains parts of the doctoral thesis of Franziska Meyer at the Universitätsmedizin Mainz/ Johannes Gutenberg-Universität Mainz.

Publisher's Note Springer Nature remains neutral with regard to jurisdictional claims in published maps and institutional affiliations.

The original article can be found online at https://doi.org/10.1007/ s00268-019-05220-7.

T. J. Musholt

musholt@uni-mainz.de

1 Endocrine Surgery, Clinic of General, Visceral- and Transplantation Surgery, University Medical Center University Mainz, Langenbeckstr. 1, 55131 Mainz, Germany

2 Endocrinology and Metabolic Diseases, University Medical Center University Mainz, Langenbeckstr. 1, 55131 Mainz, Germany

3 Institute of Pathology, University Medical Center University Mainz, Langenbeckstr. 1, 55131 Mainz, Germany 